make a legitimate protest without fear or favour is no longer considered wise.

Truro,

Comwall TR4 9QS

1 Calman K. The profession of medicine. $B M 7$ 1994;309:1140-3. (29 October.)

2 Butt G. Iraqi doctors face climate of fear. BMF 1994;309:898. (8 October.)

\section{Unanimity in the profession}

\section{Don't pretend to be unanimous}

EDIToR,-The first two editorials in the issue of 29 October sit strangely together. While the first, by Ian Morrison and Richard Smith, takes an imaginative view of the future, ${ }^{\prime}$ the second, by Tony Grabham, is a fine example of the authoritarian and corporatist attitude that has characterised "doctors' leaders" for too long. ${ }^{2}$ Morrison and Smith urge doctors to see themselves as part of a wider society, characterised by sophisticated consumers and shifts in the boundaries of health and medicine. Grabham, however, reminisces back to the days of Harold Wilson and Barbara Castle, when a display of professional unity apparently influenced government policy.

If the profession is unanimous then there is no point arguing for unanimity. If it is not then the pretence of unanimity if a deception. I reject the notion that breaking ranks and expressing a contrary view is wrong. It is about time that medical leaders (and the public) stopped regarding medicine as a professional island, unaffected by the tides of social change. On the contrary, as doctors we reflect the range of opinion present in the society from which we are drawn. Doctors therefore have every right to express personal views publicly, even when these are at variance with those of the ruling medical cabal. When I was a medical student in Johannesburg I marched in the streets in defence of academic freedom, and I will continue to oppose any threat to this principle, whether from the government or from professional leaders.

Policymakers are entitled not only to information on the majority view in the profession but also to the degree of unanimity and the reasons behind opposing medical viewpoints. Grabham is right that medical representatives are fragmented. An academy of medicine based on the royal colleges and elected representatives would form a useful point of contact between the government and the profession and a forum for reasoned argument, particularly in cases in which consensus is absent. Such an academy should not simply try to paper over the cracks of inevitable and healthy division of opinion.

$$
\text { RICHARD J LILFORD }
$$

University of Leeds,

Leeds LS2 9LN

1 Morrison I, Smith R. The future of medicine. BMF 1994;309: 1099-100. (29 October.)

2 Grabham T. Divided we fall (yet again). BMf 1994;309:1100-1. (29 October.)

\section{Any academy should stay away from realpolitik}

EDITOR,-When Tony Grabham confines himself to ethical issues (incidentally, I believe that performance related pay in medicine is primarily an ethical issue) I broadly agree with his view that the profession needs to present a united front. ${ }^{1}$ The BMA's ethical committee has worked wonders over the past few years, but the BMA's council does not provide the ideal forum in which to debate the broad issues: time for reasoned debate is rarely adequate, the adversarial presentation of amendments and riders is often too restrictive, and the council anyway is predominantly politically oriented. A policy forming body combining as its basis the views of the General Medical Council, the royal colleges, and the BMA would certainly be more authoritative and possibly more effective as well.

But the thought of such a body concerning itself with realpolitik is another matter. Firstly, the government would seize on it as the ultimate longstop, declining to make any important medicopolitical decisions until they had been referred to this particular committee; this would effectively emasculate the standing committees of the BMA, which over the years have been remarkably effective. Secondly, the committee, elected I know not how, would have a high proportion of academics, who are not renowned for their political wisdom, and if truly representative would be vast. Almost by definition the members would be "yesterday's men" and disproportionately old. The committee could be answerable only to its constituent parts, which on many issues would be at variance with each other, and the mind boggles at the thought of drawing up a timetable when all the members would be free to meet.

I accept that politically the profession has not done well over the past few years, but we have only ourselves to blame. The BMA represents more than three quarters of the medical profession in Britain; if its members are agreed on a policy, and if it has wise and resolute leadership, its forces are irresistible and there is no need for yet another committee to be interposed between it and the government.

TONY KEABLE-ELLIOTT

Ibstone, Former mem

High Wycombe HP14 $3 \mathrm{XX}$

1 Grabham T. Divided we fall (yet again). BMF 1994;309:1100-1. (29 October.)

\section{The future of public health}

\section{Further economic growth may not improve} health

EDITOR,-I dispute Raj Bhopal's contention that further rises in economic strength are necessary to improve the nation's health.' This rests on two assumptions: firstly, that further increases in gross national product will lead to further increases in health and, secondly, that when a country becomes more prosperous all its citizens benefit equally. I believe that the first will not hold true in the future, while the second is clearly not true even now, socioeconomic differences in health being well recognised. ${ }^{2}$

It is indisputable that higher living standards have made us healthier over the past century, but is it possible to say that this relation will hold for the future? Most of us already enjoy a more than adequate standard of living, and I cannot understand how further increases in the national wealth will make us healthier still. On the contrary, I suggest that these would be positively damaging to our health, for the creation of wealth depends on industrial processes that increase environmenta pollution, and the extra spending power that results tends to be used not on items that enhance health but on new cars and consumer goods that contribute to our society's ever increasing energy consumption. Furthermore, as the resources on which even our current lifestyle depends are finite, that lifestyle, with its health benefits and material benefits, is ultimately unsustainable. Further increases in consumption, which the politicians' talk of exponential economic growth jmplies, would merely bring closer the point at which our raw materials are exhausted while worsening both our health and our quality of life. ${ }^{3}$

The relation between the environment, income, and health is now being reflected in the scope and activities of public health as a discipline, ${ }^{45}$ but all clinicians see the effects on health of our sick environment. Surely we should be working towards industrial, employment, transport, and building policies that develop sustainable ways of living without depleting the earth's resources. Doctors proved themselves surprisingly political in the fight against smoking. Will they take arms against similar big business interests and government inertia to clean up our environment and encourage them to promote ways to make us healthier, though not necessarily wealthier, in the years to come?

Stepping Hill Hospital

ANDREW SMITH

Stockport SK2 7JE

1 Bhopal R. Past and future influences on public health. $B M$ 1994;309:1156. (29 October.)

2 Davey Smith G, Egger M. Socioeconomic differentials in public health. BMF 1993;307:1085-6.

Douthwaite R. The growth illusion. London: Resurgence Books, 1992.

4 Ashton J. Sanitarian becomes ecologist: the new environmental health. BMF 1991;302:189-90.

5 Thompson E. The woman on the kerb. BMF 1994;309:141-2 (16 July.)

\section{Evidence based public health}

EDITOR,-I am surprised that Stephen Watkins thinks that those who seek "objective measures of health gain, efficiency, and effectiveness" are a threat to public health. ${ }^{1}$ In his opinion this model is a poor substitute for professional judgment because "not all human experience is measurable in numbers, and that which is not may be more important than that which is." Surely, many of the most important aspects of human experience relevant to public health-namely, death, disease, and disability - can be measured. As for the rest, I concur with Lord Kelvin's observation: "until you have measured it, you don't know what you are talking about."

In their editorial on the future of medicine Ian Morrison and Richard Smith argue that evidence based medicine will transform the practice of medicine. ${ }^{2}$ I would argue that professional judgment in the absence of data is a poor basis for the future of public health. Evidence based public health would be a more secure foundation.

AN ROBERTS

Department of Community Paediatric Research, Research fellow

Montreal Children's Hospital,

McGill University,

Montreal,

Canada H3H 1 P3

1 Watkins SJ. For debate: public health 2020. BMF 1994;309: 1147-9. (29 October.)

2 Morrison I, Smith R. The future of medicine. BMF 1994;309: 1099-100. (29 October.)

\section{Forget the old days of medical officers of health}

EDrToR,-Stephen J Watkins advocates a return to public health paternalism, from which, thankfully, the specialty has begun to move in recent years. Despite his assertion that public health doctors cannot work with "arbitrarily defined populations" in the same way as they can with "communities," the community that holds centre stage in the article is one based on the boundaries of local government-a clear example of boundaries that are not defined by the population within them.

More careful analysis of the text shows that this reflects the fact that the community that has centre place in Watkins's allegiance is a community not of ordinary residents but of bureaucrats. After all, 